\title{
Precisamos de uma Base Nacional Comum Curricular?
}

\author{
William de Goes Ribeiro \\ Clarissa Bastos Craveiro \\ Universidade Federal Fluminense
}

\section{Resumo}

Tensões sobre currículo são constantemente reiteradas, não havendo um deslocamento do passado que ressurge anacronicamente nas políticas. Os sentidos são gerados através da circularidade dos contextos e da busca pela hegemonia. A condição de abertura da significação é o que constitui o social e nos permite pensar na hibridização de políticas curriculares recentes, as quais têm mobilizado um status de autoridade inexorável com relação à padronização. Nesse contexto, trouxemos à baila sentidos que têm se tornados hegemônicos no cenário político, como a exigência de competências e habilidades a priori para a formação de professores e de alunos.

Palavras-chave: Base Nacional Curricular Comum. Currículo. Formação de Professores. 


\section{Necesitamos de una Base Nacional Común Curricular?}

\section{Resumen}

El estrés en los planes de currículo se repite constantemente, si no hay un cambio en el pasado que resurge de manera anacrónica en las políticas. Los significados son generados a través de la circularidad de los contextos y la búsqueda de la hegemonía. La condición de apertura del significado es lo que constituye lo social y nos permite pensar acerca de la hibridación de las políticas curriculares recientes, las cuales han movilizado un estatus de autoridad inexorable con relación a la estandarización. En este contexto, hemos traído a discusión significados que se han vuelto hegemónico en la arena política, como la exigencia de habilidades y capacidades a priori para la formación de profesores y estudiantes.

Palabras clave: Base Nacional Curricular Común. Currículo. Formación de profesores.

\section{Do we need a Common National Curriculum Base?}

\section{Abastract}

Tensions about curriculum are constantly reiterated, with no displacement of the past resurfacing anachronistically in politics. The meanings are generated through the circularity of contexts and the search for hegemony. The condition of openness of meaning is what constitutes the social and allows us to think of the hybridization of recent curricular policies, which have mobilized a status of inexorable authority with regard to standardization. In this context, we have brought to the table meanings that have become hegemonic on the political scene, such as the requirement of a priori competences and skills for the training of both teachers and students.

Keywords: Common National Curriculum Base. Curriculum. Teacher training. 


\section{Avons-nous besoin d'une Base Curriculaire Nationale Commune?}

\section{Resumé}

Les tensions sur les programmes d'enseignement se répètent constamment, n'ayant pas une rupture du passé qui resurgisse anachroniquement. Les sens sont générés par conventions à travers la circularité des contextes et la recherche de l'hégémonie. La condition d'ouverture du sens est ce qui constitue le social et nous permet de penser à l'hybridation récente des politiques curriculaires lesquelles ont généré un statut d'autorité incontestable en matière de standardisation. Nous avons abordé des sens qui sont devenus hégémoniques l'arène politique, comme la demande de compétences et de capacités a priori pour la formation des enseignants et des étudiants.

Mots-Clés: Base commune de programmes d'enseignement. Curriculum. Formation de Professeurs.

\section{Introdução}

No Brasil, muito se tem debatido, em diferentes momentos históricos, a respeito de políticas de centralização do currículo, entre as quais se insere a produção de uma Base Nacional Comum Curricular (BNCC). Trata-se de definir "o essencial" para toda a educação básica, o que significa construir de maneira supostamente objetiva "a melhor formação para as nossas crianças e jovens"1, compreendendo que é uma condição necessária para garantir os direitos de aprendizagem dos alunos e a qualidade da educação. Para o Ministério da Educação (MEC)2:

A Base Nacional Comum Curricular (BNC) vai deixar claro os conhecimentos essenciais aos quais todos os estudantes brasileiros têm o direito de ter acesso e se apropriar durante sua trajetória na Educação Básica, ano a ano, desde o ingresso na Creche até o final do Ensino Médio. Com ela os sistemas educacionais, as escolas e os professores terão um importante instrumento de gestão pedagógica e as famílias poderão participar e acompanhar mais de perto a vida escolar de seus filhos. A Base será mais uma

1 Cf. texto introdutório das duas primeiras versões da BNCC de autoria de Renato Janine Ribeiro, ex-ministro da Educação.

2 Cf. http://basenacionalcomum.mec.gov.br/\#/site/base/o-que 
ferramenta que vai ajudar a orientar a construção do currículo das mais de 190 mil escolas de Educação Básica do país, espalhadas de Norte a Sul, públicas ou particulares. Com a BNC, ficará claro para todo mundo quais são os elementos fundamentais que preci sam ser ensinados nas Áreas de Conhecimento: na Matemática, nas Linguagens e nas Ciências da Natureza e Humanas.

No entanto, a ideia de se padronizar o ensino e a educação tem sido problematizada no campo curricular, o qual vem destacando: a impossibilidade de uma unidade essencial para o currículo, considerando os complexos jogos de poder que buscam ocultar a abertura da significação (Cunha, 2015), bem como a complexidade do contexto da prática (Cunha; Da Silva, 2016); as articulações público-privadas, bem como novas formas de sociabilidade que projetam o imponderável para fora, configurando uma intensificação regulatória baseada na avaliação centralizadora, como propõem os modelos privados de gestão (Macedo, 2014); o controle social que se dá por intermédio de políticas que ressignificam o eficientismo em uma separação questionável entre a produção e a implementação. (Lopes; Macedo, 2011)

Assim, os referidos pesquisadores põem em destaque as exclusões de sentidos mobilizadas pela exigência de uma BNCC, entendida como uma crença na superação do que seria supostamente uma anomia curricular no Brasil. Tal discurso mobiliza uma garantia de ordem, isto é, de se ensinar tudo aquilo que se considera necessário que os alunos aprendam, atualizando a significação do currículo, do trabalho docente e da escola na linha accountability (Pereira; Costa; Cunha, 2015). Conforme ressaltam os citados autores, os resultados de testes padronizados dizem respeito à (in) capacidade da escola, contexto este em que os professores deverão ser (mais) avaliados em função de expectativas de resultados e de metas que se tornam cada vez mais inexoráveis.

Para o MEC uma Base é imprescindível ${ }^{3}$ :

A necessidade de criação de uma Base Nacional Comum aparece na nossa Constituição Federal, de 1988, no Art. 210. Anos depois, ela também é prescrita na Lei de Diretrizes e Bases da Educa ção Nacional (LDBEN), em seu artigo 26. Nas Diretrizes Curriculares Nacionais (DCNs) é que a Base é efetivamente detalhada. E é a partir das DCNs que todo o processo atual de construção da BNC se inspira e se organiza. Mais recentemente a necessidade da BNC foi evidenciada ainda em outros documentos significativos para a Educação, frutos de discussões de todos os setores da sociedade. Ela está indicada nas Conferências Nacionais de Educação e também no Plano Nacio nal de Educação (PNE). O PNE estabelece, em diversas estratégias, a construção de uma proposta de Direitos e Objetivos de Aprendizagem e Desenvolvimento, coordenada pelo MEC, e que deve ser encaminhada, até junho de 2016, para o Conselho Nacional de Educação (CNE). O atendimento a essas determinações legais - Constituição, LDBEN, DCNs, CONAE e PNE - terá como efeito a produção de uma referência de currículo que articule os esforços existentes nos estados, no Distrito Federal e em muitos municípios na produção de seus documentos curriculares.

3 lbidem. 
No entanto, o que permanece oculto nesta linha do tempo são as vozes dissonantes e as contradições da política, conforme destaca Macedo (2015). A mencionada autora lembra que, no contexto de produção dos PCNs, Fernando Henrique Cardoso (FHC) tinha a intenção de tornar os parâmetros a Base, o que não teve a aprovação do Conselho Nacional da Educação. Apesar de uma regulação indireta, eles foram produzidos como não obrigatórios. Ou seja, alternativas às interpretações da legislação são possíveis.

Por sua vez, algumas articulações políticas ligadas à educação, como o Movimento pela Base Nacional Comum4, têm atribuído ênfase na legitimação de um "currículo nacional", um documento de qualidade, baseadas em estudos de casos "bem sucedidos":

O Movimento pela Base Nacional Comum é um grupo não governamental de profissionais da educação que desde 2013 atua para facilitar a construção de uma Base de qualidade. O grupo promove debates, produz estudos e pesquisas com gestores, professores e alunos e investiga casos de sucesso em vários países.

Pesquisadores como Alves (2014), Lopes (2015), Macedo (2014, 2015), Marchelli (2014), Süssekind (2014), dentre outros, salientam que não se trata de uma discussão nova no país, mas tem sido impulsionada a partir da publicação do PNE (20142024), o qual estabelece como Plano Nacional as metas e as estratégias para a educação (Brasil, 2014). Nesse contexto, há uma ênfase na interpretação de que a Base Nacional Comum Curricular (BNCC) é um instrumento indispensável para a qualidade e para o cumprimento do referido plano. Nessa discussão, Craveiro (2014a, 2014b) problematiza a referida e a reiterada tentativa de padronização curricular, argumentando que alguns discursos hegemônicos têm sido defendidos desde os anos 1990 e mantidos nas proposições da BNCC.

Tendo como referência estudos do currículo no Brasil (Lopes; Macedo, 2011), salientamos que os sentidos produzidos nos contextos dos governos de Fernando Henrique Cardoso, Luis Inácio Lula da Silva e da presidenta Dilma Rousseff convivem com diferentes discursos que são reinterpretados ao mesmo tempo em que recriam novas remobilizações culturais. No entanto, os aspectos relacionados à BNCC recontextualizam esses três contextos, sendo necessariamente reiterados em um novo contexto (Michel Temer) no qual a Base se encontra "sob nova direção" (Freitas, 2016), tendo como uma das principais mudanças, já anunciadas pela terceira versão, um documento estruturado por competências ${ }^{5}$.

Em tal configuração, enfatizamos que determinados sentidos de formação docente e de currículo que vinham sendo naturalizados, tendem a manter as projeções, porém alicerçadas agora em uma perspectiva de competências a priori para adequação dos

4 Cf. http://movimentopelabase.org.br/

5 Cf. http://movimentopelabase.org.br/ 
alunos, a qual possivelmente intensifica a "cultura da testagem" que ignora o campo do currículo como produção acadêmica (Miller, 2014). Pesquisadores do campo do currículo como Lopes (2015) e Macedo (2014) mencionam que nesse cenário político determinados sentidos hegemônicos de formação de professores atravessam a discussão em defesa de uma base curricular no Brasil, hoje, com um avanço mais notado do conservadorismo nas políticas curriculares ${ }^{6}$.

No que se refere à produção de um documento curricular centralizador, levantamos as seguintes questões: ele é necessário? Precisamos de uma BNCC? Trata-se de algo indispensável para se atingir a qualidade educacional? Estamos realmente discutindo uma demanda educacional indispensável? Com tais questões destacadas, organizamos este texto: em um primeiro momento, destacando o quadro teórico que tem nos permitido analisar as tensões e as questões elaboradas. A seguir, nos detemos em alguns dos sentidos a respeito da Base. Posteriormente, excessiva ênfase no contexto de influência, não se distanciando em alguns aspectos da abordagem estadocêntrica que desejava superar. Desta forma, apesar de valorizar uma maior complexidade do jogo político, Ball não supera a separação entre proposta e implementação, tendendo a atribuir ênfases ao contexto de influência como "início" da política (Oliveira; Lopes, 2011), o que acaba recaindo sobre o contexto da prática a possibilidade de mudança (Craveiro, 2014b). Ora, isso contradiz a perspectiva de ciclo, já que o mesmo não poderia apresentar nem início e nem fim. As autoras anteriormente citadas também salientam a ausência de explicação nos ciclos de política de como ocorrem predominâncias de interpretação nos documentos curriculares, deixando lacunas no que tange ao processo em que as lutas se dão. Embasado por Michel Foucault, Ball entende que os discursos são construídos continuamente, são incontroláveis e não se limitam a materialidade do texto. Porém, o sociólogo mantém uma separação questionável, hierarquizando termos e contextos; não compreendendo que não há nada fora do jogo discursivo, algo relevante no trabalho de Ernesto Laclau. A Teoria do Discurso pode então aprofundar a interpretação do ciclo de políticas, uma vez que faltam em Ball categorias que possam dar conta dos processos articulatórios que se inserem na definição das políticas em ciclos contínuos (Lopes; Macedo, 2011; Oliveira; Lopes, 2011).

A Teoria do Discurso tem sido apropriada no campo do currículo como uma ferramenta relevante de análise na medida em que permite novas formas de investigação frente à complexidade dos contextos multiculturais, abrindo o enfoque para o entendimento das articulações que garantem a constituição de um discurso (Laclau; Mouffe, 2015; Laclau, 2013), como visto, aspecto este não explorado por Ball. Segundo Mendonça e Rodrigues (2008), a teoria do discurso é inaugurada por Laclau e Mouffe na obra Hegemony and socialist strategy: towards a radical democratic politics, publicada em 1985. Enfatizam os autores citados tratar-se de uma ferramenta de compreensão do

6 Cf. dossiê temático: http://www.e-publicacoes.uerj.br/index.php/revistateias/issue/view/1347 
social, cuja centralidade é o discurso e o poder, os quais se desdobram em noções relevantes como articulação, hegemonia, antagonismo, lógicas da diferença e da equivalência, dentre outras. Nessa perspectiva, não há práticas que não sejam discursivas e vice-versa, entendendo que

discurso não é apenas linguagem, envolve ações e instituições, sendo o funcionamento do social compreendido como uma linguagem. Dessa forma, a teoria do discurso visa não separar a linguagem (retórica), o indivíduo (sua psique) e o político (a sociedade e o social). (Lopes e Macedo, 2011, p. 10)

Conforme salienta Lopes (2015), não se trata de negar a materialidade, mas que tudo é envolvido em uma dimensão do discurso, como dito não é apenas linguagem, mas uma prática social. Nesse entendimento, o contexto não é um dado a priori, mas ele mesmo produzido discursivamente. Assim, não há entendimento da realidade que não demande uma passagem pelo discurso, pelo sentido, pela inserção de fatos físicos, sejam eles humanos ou naturais, em sistemas de significação que situem e hierarquizam esses fatos no mundo e participem da disputa pela significação (Burity, 2008; Giacaglia, 2006).

Portanto, com base nos autores que compõem o quadro teórico-metodológico, cultura não é um "repertório de significados já dados por grupos distintos" (Lopes; Macedo, 2011), mas complexos "fluxos culturais" (Appadurai, 2004), ou seja, são práticas de significação (Ribeiro, 2016), por meio das quais ocorre a hibridização, intensificadas no contexto atual ${ }^{7}$, o que nos conduz ao currículo como espaço-tempo de fronteiras (Macedo, 2006a, 2006b, 2009). Currículo é também uma política cultural, uma vez que a política, com base nesta abordagem, é entendida como disputas entre discursos em busca do poder de fixar um sentido. Assim, cultura e política estão imbricadas, uma vez que a política ocorre neste entre-lugar ambivalente da negociação que é a remobilização de sentidos (Bhabha, 1998). Trata-se sempre de uma negociação com a alteridade de si, o que jamais estará dado (Derrida, 2011). Para o filósofo, não há relação necessária entre significante e significado, este último é sempre postergado para a relação circunstancial.

Nessa perspectiva de diálogo com leituras pós-estruturalistas, hegemonia foi ressignificada por Laclau. Não se trata de um sentido no qual determinada ideologia se torna comum a um coletivo (Laclau; Mouffe, 2015; Lopes; Macedo, 2011). Um discurso particular se torna hegemônico no momento em que ocupa o lugar do universal (Laclau; Mouffe, 2015; Laclau, 2013; Mendonça; Rodrigues, 2008). Para que isso ocorra são necessárias "articulações", entendidas "como uma prática que estabelece um tipo de relações entre elementos que faz com que a identidade dos mesmos se modifique como resultado da prática articulatória" (Giacaglia, 2006, p.

7 Estamos nos referindo a questões ligadas a intensificação dos fluxos culturais através de novos arranjos na comunicação, gerados pelas novas tecnologias e por movimentos de imigração no processo atual da globalização. Mais detalhes são discutidos por Appadurai (2004). 
106). Nesse sentido, frente ao discurso que se torna hegemônico, haverá outros discursos que podem, a despeito das diferenças entre si, configurarem uma cadeia de equivalências, unidos pelo antagonismo.

\section{Com relação à necessidade...}

$\mathrm{Na}$ atual seção do trabalho, reunimos argumentos que julgamos pertinentes em relação à problemática de uma referência curricular nacional. Com isso, pretendemos destacar uma questão que não tem sido posta com frequência: a necessidade da BNCC. No que tange à perspectiva centralizadora, formação docente, currículo e avaliação se articulam ao discurso de uma unidade nacional imaginada (Appadurai, 2004), o que configura necessariamente um processo de exclusão. Nesse sentido, temos interesse em compreender os possíveis efeitos que tais políticas curriculares produzem como centralização curricular neste jogo político.

Levado em considerando o exposto, um dos problemas diz respeito ao que se entende por uma BNCC. Alves (2014) ressalta que seria preciso muita discussão para que se tenha um mínimo acordo. Com relação aos sentidos, Macedo (2014) destaca os que têm circulado nas redes políticas: "conteúdos" (poderosos e/ ou socialmente elaborados); "direitos de aprendizagem"; "expectativas de aprendizagem"; "padrões de avaliação". E infere a autora que tais sentidos se articulam discursivamente, transformando objetivos em padrões e padrões em objetivos, produzindo uma nova forma de sociabilidade na qual está em jogo uma maneira de regulação que se dá por intermédio da avaliação, buscando expulsar o imponderável que constitui o processo educativo. Em 2015, a referida pesquisadora publica um artigo em que salienta, neste jogo, sentidos de educação que articulam direito público subjetivo e bem privado (performance medida pelo Estado), o que produz uma compreensão normativa de currículo, a partir da qual procura-se ignorar a imprevisibilidade do "chão da escola" (Macedo, 2015). Miller (2014), no contexto estadunidense, denomina a política em questão de "cultura da testagem", isto é, conforme realçado em seção anterior, trata-se de uma retomada do tecnicismo, a partir de novas bases ou articulações contemporâneas. Conforme anuncia o Movimento pela Base, a BNCC terá como principal mudança na terceira versão a organização por competências.

Com efeito, empenhar-se no desenvolvimento de uma referência curricular é também construir uma perspectiva tendo como eixo organizador a ideia de "nação" (todos no um da nação), seja ela física (territorial) e/ ou simbólica. Bhabha (1998) oferece possibilidades de desconstrução deste discurso, ajudando-nos a compreender que não há tentativa de fixação que não passe pela hibridização. Trata-se de um processo ambivalente que se dá sempre nos interstícios da enunciação, mediante negociação 
constante de sentidos com a alteridade. Ou seja, tais processos de construção do nacional não estão dados ou elaborados a priori, são também efeitos de relações de poder. Deste modo, Bhabha se opõe a quaisquer inversões simples de polaridades identitárias, ou seja, binarismos essencialistas, a partir dos quais centralizaríamos uma agenda. Os sentidos de nação são sempre articulados reiteradamente mediante o processo discursivo, apesar de eles costumarem ser ansiosamente sustentados na "lápide fixa das tradições". De outro modo, ao invés de reproduzirmos a lógica enclausurada e binarista que perfaz comumente a economia política, o pesquisador propõe atentarmos para um tempo revisionário, isto é, para o entre-lugar da negociação discursiva que constitui a subjetividade, o que torna problemática a referência a um sentido único e autossuficiente de nação. Em termos laclaunianos, diferentes sentidos do nacional são objetos de luta pela hegemonia. Na Teoria do Discurso, como vimos, o que se configura hegemônico ocorre quando um sentido particular (no caso, do nacional) ocupa o lugar impossível da totalidade, gerando antagonismos, os quais seriam outros discursos particulares prejudicados de alguma forma nesta configuração.

Deste modo, ao considerar tais embasamentos teóricos, uma base curricular nacional como objeto pronto é, portanto, impossível. Um currículo nacional será sempre resultado de uma operação de poder em que outros sentidos "do nacional" imaginados, e com isso outras demandas em nome deste significante se fragilizam; mas também podem, apesar das diferenças, gerar equivalências frente ao discurso hegemônico. Entendendo o currículo como uma prática de significação, como cultura, reafirmamos que uma base nacional subestima a interação social e a diferença, inclusive ignorando a multiplicidade de demandas.

Sendo assim, afirmar que "a parte diferenciada" do currículo dará conta das questões locais é uma grande falácia, já que todo o currículo se localiza pela enunciação. Portanto, trata-se de uma estratégia de deslocar a diferença para a margem, como bem destacou Macedo (2009) em outro momento a respeito dos temas transversais. Além disso, consideremos as regulações por meio das avaliações em larga escala, a partir das quais "o mínimo se torna o máximo" (Pereira e Oliveira, 2014). No contexto da prática, os sentidos são remobilizados, hibridizados, não havendo possibilidade de previsão e/ ou cálculo a não ser por um processo ilusório e um ato de poder que culpabiliza, em uma abordagem dual, a implementação. A consulta pública é deste modo uma estratégia de legitimação. A partir dela, se ganha adesão, configurando um discurso de respeito à participação e à diversidade.

Lopes (2015) argumenta que não há fundamento absoluto, científico ou não, para a de centralização é arbitrariamente definida, dependente de uma série múltipla de leituras, pois os contextos também não são espaços dados com fronteiras definidas, existentes no mundo, mas construções discursivas no/ do mundo. As perguntas "comum e essencial, para quem?" e "direitos de ensino e aprendizagem, para quem?" (Macedo, 
2015) se fazem, portanto, pertinentes. O que é visto supostamente como "comum" e/ ou "essencial" é sempre uma produção-exclusão no campo da discursividade. Há sempre algo que ficará "de fora", um exterior constitutivo (como as questões relativas à valorização do magistério). Conforme Lopes (op. cit.): "a produção de centros e contextos da política (de currículo) depende de atos de poder, constitui e é constituída por - certos discursos (pedagógicos)" (p. 447). Em suma, definir um "comum nacional" é uma forma de regulação e de controle da diferença.

Identificamos no atual governo um cenário de reformas autoritárias e de investimentos midiáticos que têm buscado ocultar o binarismo nas políticas (formação para pobres e para ricos). O que se busca é convencer de que a reforma que estão fazendo é necessária e de que se está favorecendo a liberdade de escolha. Destacamos ainda investidas de setores conservadores reacionários na política curricular (Paraíso, 2016), tais como o movimento Escola sem Partido (ESP), os quais vêm produzindo inúmeras medidas para regulação da liberdade de ensino, articulando o silenciamento do debate de gênero por meio da ideia de que se estaria promovendo ideologias. Nesse contexto, o argumento que procuramos defender em bases epistemológicas de matriz pós-estrutural, de que a BNCC é uma investida desnecessária e temerosa, se renova politicamente, apontando os riscos de uma centralização nacional e o quanto o discurso "de que padronizar é democratizar o ensino" pode ser favorável a determinados grupos.

Portanto, questionamos a respeito da necessidade da base, isto é, não apenas de um ou outro aspecto do referido documento que poderia, ou não, ser melhorado. Nossa questão antecede a esta, a saber: por que motivo investir recursos financeiros tão volumosos para produção de mais uma proposta curricular? Qual é a necessidade de uma base? Garantia de qualidade para educação? Como?

Segundo Alves (2014), na opinião da maioria dos que estudam currículo no Brasil é de que não precisamos de base curricular nacional. Ela realça e retoma alguns dos motivos já informados anteriormente: trata-se de uma importação de modelos que desconsidera os contextos e singularidades; tem como enfoque um referencial questionável de escola igual para todos; não atende aos questionamentos dos antagonismos que vem sendo gerados ao longo do tempo em termos de políticas setoriais, tais como as referentes à educação infantil, educação quilombola, educação indígena e outras. A autora problematiza ainda a ilusória interpretação de que tudo será resolvido a partir de uma BNCC e reforça a necessidade de atribuirmos ênfase a outras metas e estratégias do novo PNE, tal como a meta 18, a qual se refere aos planos de carreira e salarial do magistério, afinal de contas, provoca a pesquisadora, serão os docentes os culpabilizados pelos supostos fracassos.

Com relação à subjetividade docente, Süssekind (2014) enfatiza, com base em William Pinar, que um dos principais efeitos desta centralização curricular é a demonização do professor, uma vez que as expectativas traçadas em torno deste documento 
são impossíveis de se concretizar de maneira homogeneizada. Em perspectiva esta questionável, o currículo é compreendido como um objeto, uma arma, para mudar as mazelas da sociedade, criando uma expectativa-projeção salvacionista. Processos são tratados assim como objeto, servindo aos anseios da mercantilização em um cenário de reformas neoliberais.

Sobre anseios de mercado, há outras considerações a serem feitas. Através de uma análise das redes, Macedo (2014) identifica uma interferência privada nos setores educacionais públicos. Nesse sentido, as parcerias entre público e o privado diluem fronteiras, antes, talvez, mais perceptíveis. Novas formas de governamentalidade são enfatizadas e criadas, enfatiza a autora, sobretudo com a tentativa de se retirar da educação o imponderável que lhe constitui. A ênfase recai sobre uma perspectiva de ensino na qual o currículo é apenas um objeto, excluindo as mediações dos atores que o produz. No referido estudo, a pesquisadora ressalta ainda que uma base curricular serve aos propósitos de controle que no limite reduz as possibilidades da educação acontecer, já que tal processo depende de um trabalho com a singularidade, com o incontrolável, com as incertezas, com as subjetividades.

Apesar das considerações dos pesquisadores em currículo e dos debates elaborados anteriormente, por intermédio de sentidos de formação hegemônicos no Brasil, podemos inferir que a defesa da BNCC vem sendo gestada há décadas por meio de estratégias e naturalização de discursos que defendem que é imprescindível para o professor uma seleção de saberes e conhecimentos significativos, a utilização de metodologias inovadoras e um desempenho competente (Brasil, 2013). Nesse sentido, perpetua-se uma abordagem cindida entre quem pensa, quem administra e quem executa o currículo, estes últimos sendo os culpabilizados no percurso, quando é a própria "lógica" o problema.

\section{Sentidos de Formação de Professores}

Nesta seção, partindo das discussões sobre a formação de professores em Craveiro (2014a, 2014b), destacamos alguns comentários a respeito da meta e estratégia 15 do Plano Nacional de Educação (PNE) finalizado em 2014, que articula a necessidade da base comum nacional como forma de garantir a qualidade da educação.

A modulação e flutuação dos discursos defendidos por meio dos documentos produzidos nos contextos políticos dos governos Fernando Henrique Cardoso (FHC), Lula da Silva (Lula) e Dilma Rousseff (Dilma) buscaram fixar alguns paradigmas que associavam a "qualidade" e/ ou mudança na educação oportunizada pela competência 
eficiente dos professores na sala de aula e assegurada também por uma formação "competente". Dessa maneira, foram sendo hegemonizados determinados discursos que padronizavam o "professor competente". Nesse sentido, o discurso na BNCC pautado pela meta e estratégia 15 do PNE traz aspectos já defendidos nos contextos FHC, Lula e Dilma. Tais demandas, de certa forma, hegemonizadas no contexto pedagógico como o das competências, atribuem importância à aquisição e ao domínio de determinados conteúdos por parte de professores o que "garantirá" um aprendizado competente por parte dos alunos, a necessidade de avaliações e índices para aferir a proficiência. Todavia, essa aproximação de sentidos apenas aborda as cadeias articulatórias dos três contextos, aproximando as fronteiras dos seus projetos políticos.

No extenso período dos contextos FHC, Lula e Dilma, o discurso hegemônico da aquisição de conteúdos, significado por diversas maneiras, não tem sido capaz de trazer a tão almejada qualidade da educação. Craveiro (2014a, 2014b) defende que os discursos dos contextos FHC e Lula aproximam-se por meio das demandas das avaliações, dos padrões internacionais e dos índices de qualidade para a formação docente. $O$ discurso que legitima as avaliações institucionais externas para sinalizar para a sociedade como a escola, ou melhor, como a Educação Básica está e também para certificar a formação profissional dos professores apresenta o respaldo de organismos como Organização para a Cooperação e Desenvolvimento Econômico (OCDE), Fundo Monetário Internacional (FMI) e UNESCO. No contexto Dilma, esse respaldo quanto à certificação também é legitimado por parceiros privados como Instituto Natura, Fundação Lemann, parceiros herdeiros do banco Itaú, conforme Macedo (2014) destaca nos discursos em defesa da base comum nacional.

O discurso da meta 15 do PNE busca garantir "que todos os professores e as professoras da educação básica possuam formação específica de nível superior, obtida em curso de licenciatura na área de conhecimento em que atuam". Até aqui, corrobora com a formação de nível superior proposta na LDBEN 9394/96, todavia, em suas estratégias 15.6 e 15.7 o foco do discurso destaca que os currículos da educação básica "configurarão a base nacional comum curricular do ensino fundamental" (cf. estratégia 2) e também "objetivos de aprendizagem e desenvolvimento que configurarão a base nacional comum curricular do ensino médio" (cf. estratégia 3).

Compreendemos que tais discursos podem ser significados como um fechamento provisório ${ }^{8}$, hegemônico, em defesa dos conteúdos já mencionados desde os diferentes contextos políticos. Tais articulações fazem com que esses contextos (FHC, Lula e Dilma) se aproximem e até diminuam a fronteira antagônica entre os mesmos (Craveiro, 2014a). Todavia, buscamos entender as modificações e articulações de sentidos do projeto social Dilma, pois, aparentemente, aproxima-se mais do contexto FHC do que do contexto Lula uma vez que explicita a necessidade de conteúdos e

8 Cf. Laclau (2013). 
avaliações em alguns de seus discursos e propõe uma "nova arquitetura de regulação" (p.1549).

Destacamos que o PNE (2014) no que diz respeito "a área do saber e didática específica" aproxima-se mais do discurso defendido no contexto FHC que do discurso do contexto Lula" como "um dos grandes desafios da formação de professores é a constituição de competências comuns aos professores da Educação Básica e ao mesmo tempo o atendimento às especificidades do trabalho educativo" (Brasil, CNE/ CP 3/2006, p.8).

O discurso do contexto Lula busca potencializar a atuação do professor da Educação Básica, apresentando outros campos de desenvolvimento como a gestão, os movimentos culturais da comunidade, o desenvolvimento com estudos e pesquisas de natureza teórico-investigativa da educação e da docência (Brasil, CNE/CP 3/2006, p.2) e, dessa maneira, conforme defende, "resgatar a identidade profissional do Magistério" (Brasil, CNE/CP 3/2006, p.3).

A meta 15.7 do PNE (2014), que traz à discussão questões atreladas à avaliação, dá margem a aproximações dos discursos do contexto FHC. Nesse sentido, a avaliação é significada como garantidora de um diagnóstico importante para a enunciação das mudanças necessárias à formação e profissionalização docente. É também considerada como um momento privilegiado para rever a teoria e a estrutura curricular e tem como finalidade última a redução da repetência e evasão dos alunos. A avaliação é, portanto, associada a um componente que auxiliará o desenvolvimento cultural, uma adequação às novas necessidades do mundo globalizado, o canal que faz um diagnóstico da formação dos professores, significando uma possibilidade de formação 'mais qualificada' que poderá potencializar um maior aprendizado dos alunos. A avaliação periódica ganha força e compreende uma das frentes capaz de garantir a defesa da possibilidade de melhorar as informações acerca do conhecimento apreendido pelos futuros professores e pelos alunos da Educação Básica, o meio de garantir a aquisição de conteúdos, sob o discurso de 'investimento' (cf. Brasil, DCN 009, 2001).

É considerado que deve haver um 'investimento' proporcionado pelas instâncias responsáveis pela formação nacional dos professores, um investimento para a sociedade que busca a melhoria de conhecimento dos alunos que estão nas escolas, um investimento por parte dos professores que proporcionará uma melhor aferição do seu conhecimento profissional e possibilidades de suprir as deficiências nesse campo, quando necessárias, por meio de programas de formação continuada. Esses sentidos da formação como investimento flutuam ao longo do discurso em defesa da avaliação.

O movimento de pensar a avaliação como possibilidade de aferição de conhecimentos

9 Retomamos que essas considerações tem por base a análise de Craveiro (2014a). 
adquiridos por parte dos professores e/ ou por parte dos alunos repercute na forma com que os professores lidam com os conteúdos, bem como na sua aquisição e desenho da matriz curricular. É recorrente a defesa do princípio metodológico de ação-reflexão-ação e resolução de situações-problema, pois o "desenvolvimento de competências pede uma outra organização do percurso de aprendizagem, no qual o exercício das práticas profissionais e da reflexão sistemática sobre elas ocupa um lugar central" (Brasil, DCN 009, 2001, p.19).

No que diz respeito às funções de "avaliação, regulação e supervisão da educação superior", o PNE (2014) aproxima-se dos discursos defendidos nos contextos FHC e Lula em aspectos que as cadeias discursivas mais se aproximam do que se afastam nos seguintes sentidos: quanto à necessidade de avaliações institucionais; quanto ao entendimento do processo avaliativo como experiência vivenciada e da autoavaliação profissional como parte do processo de aprendizagem e quanto aos padrões e índices internacionais para as avaliações nacionais.

O discurso analisado do contexto Lula apresenta textos em que se justifica o investimento na educação através de programas voltados para maior qualificação nas licenciaturas a partir de índices nacionais e internacionais. A aprendizagem dos alunos é comparada aos índices dos países da Organização para a (OCDE) e os relatórios apresentados têm por base dados do (FMI), Base de dados mundial de economia (2008), Relatório de Desenvolvimento Humano 2008/2009 do Programa das Nações Unidas para o Desenvolvimento, compilado com base em dados de 2006, Relatório de Monitoramento Global do EPT, UNESCO. Desse estudo, conforme as análises de Craveiro, partem as avaliações como SAEB (Sistema de Avaliação da Educação Básica), Prova Brasil (Avaliação Nacional do Rendimento Escolar) e ENEM (Exame Nacional do Ensino Médio), bem como a formação de professores por meio dos IFET (Instituto Federal de Educação, Ciência e Tecnologia), Universidade Aberta do Brasil (ou UAB - é um articulador entre governo federal e entes federativos que apoia universidades públicas a oferecere cursos de nível superior e pós-graduação por meio da modalidade da Educação à Distância) e Programa REUNI (Programa de Apoio a Planos de Reestruturação e Expansão das Universidades Federais).

Os sentidos de avaliação dos contextos FHC e Lula são incorporados e recontextualizados aos discursos do contexto Dilma retomando a necessidade de garantir a eficácia das propostas por meio da aferição de conteúdos. Esse discurso subsidiará a defesa pela necessidade da BNCC, ganhando possivelmente a ênfase em Temer. 


\section{Uma pausa no caminho...}

Ao longo deste trabalho, procuramos discutir a respeito dos sentidos de centralização hegemônica que se articulam na defesa de uma construção de uma base nacional comum curricular, cujos efeitos incidem sobre o currículo, sobre a avaliação e sobre a identificação docente. Procuramos fazê-lo através da desestabilização de alguns de seus alicerces, destacando o viés da regulação e do controle. O que está em jogo quando centralizamos sentidos como nacional? Como definir o comum, o essencial e o que isto significa? Direitos de aprendizagem, para quem? A qualidade será garantida por intermédio de mais uma padronização? Questões como estas perfazem nossas inquietações. Mas, cairíamos em contradição caso afirmássemos que há respostas definitivas, pois em nosso entendimento, apesar dos fechamentos provisórios, é a condição de abertura que permite o jogo político. O que não impede o destaque para alguns aspectos que podem ser considerados na análise.

Deste modo, consideramos relevante trazer à baila os sentidos que têm se tornado hegemônicos no cenário nacional em diversos contextos políticos, aos quais tem conferido ao docente a exigência de competências e habilidades - e agora também possivelmente aos alunos - em uma perspectiva salvacionista da escola em relação às mazelas sociais. Diante de tal configuração, a avaliação centralizadora torna-se um instrumento imprescindível para a regulação da operação curricular vigente. Currículo se articula aqui como uma arma transformadora e salvacionista, currículo como um documento, como um objeto, uma mercadoria. Destacamos, em contrapartida, que currículo, em nosso entendimento, é uma prática de enunciação que se dá na interação entre os sujeitos, entre professores, alunos e saberes. A ação educativa não está exime da multiplicidade por mais que se tente ocultá-las pela Torre de Babel.

Considerando o exposto, a pretensão de objetividade é ilusória, se faz por internédio de uma tentativa (impossível) de impedir novas leituras. Tal impossibilidade recai sobre docentes e alunos, uma vez que eles serão os cobrados por não corresponderem às expectativas propostas. A respeito da qualidade, pensamos que outros debates podem explicitar melhor a questão. Por exemplo, reafirmamos também antigas discussões promovidas pelos movimentos dos profissionais da educação que tomavam como Base não uma BNCC, mas a relevância dos planos de carreira do professor, a questão salarial, as condições de trabalho na escola, dentre outros elementos que não vem tendo o mesmo destaque que "o currículo messiânico" investido de necessidade e de respeito a direitos. Já há diretrizes curriculares e as tradições disciplinares de cada área, o que é suficiente para a negociação de saberes nas redes, tornando qualquer base curricular uma medida desnecessária, mas nem por isso menos isenta de discussão. No âmbito pós-estrutural de pensar o currículo talvez seja pertinente debater a questão do conhecimento e/ ou como nos inserimos em projetos sem silenciar e oprimir, sem tentar impedir o novo, sem desejar conter a criação. 


\section{Referências}

APPADURAI, Ajur. Dimensões culturais da globalização. Lisboa: Editorial Teorema, 2004.

ALVES, Nilda. Sobre a possibilidade e a necessidade de uma base nacional comum. Revista E-Curriculum, São Paulo, v.2, n.3, p.1464-1479, out./dez., 2014.

BOWE, Richard; BALL, Stephen.; GOLD, Anne (orgs.). Reforming education \& changing school: case studies in policy sociology. Londres/Nova lorque: Routledge, 1992.

BALL, Stephen. What is policy? Texts, trajectories and toolboxes. In: Education Reform: A critical and post-structural approach. Buckingham: Open University Press, 1994.

BRASIL. Parecer CNE/CP $n^{\circ}$ 9, de 8 de maio de 2001. Diretrizes Curriculares Nacionais para a Formação de Professores da Educação Básica, em nível superior, curso de licenciatura, de graduação plena. Brasília, 2001.

BRASIL. Resolução CNE/CP $n^{\circ} 1$, de 15 de maio de 2006. Institui Diretrizes Curriculares Nacionais para o Curso de Graduação em Pedagogia, licenciatura. Brasília, 2006.

BRASIL. Diretrizes Curriculares Nacionais Gerais da Educação Básica / Ministério da Educação. Secretaria de Educação Básica. Diretoria de Currículos e Educação Integral. Brasília: MEC, SEB, DICEI, 2013.

BRASIL. Lei 13.005, de 25 de junho de 2014. Aprova o Plano Nacional de Educação - PNE e dá outras providências. Brasília, 2014.

BHABHA, Homi. O local da cultura. Tradução de Myriam Ávila, Eliana Lourenço de Lima Reis e Gláucia Renate Gonçalves. Belo Horizonte: Ed. UFMG, 1998.

BURITY, Joanildo Albuquerque. Discurso, política e sujeito na teoria da hegemonia de Ernesto Laclau. In: MENDONÇA, D. de; RODRIGUES, L. P. (org.). Pós-Estruturalismo e Teoria do Discurso: em torno de Ernesto Laclau. Porto Alegre: EDIPUCRS, 2008, p. 35-52.

CRAVEIRO, Clarissa Bastos. Políticas curriculares para a formação de professores: processos de identificação docente (1995- 2010). 2014a. Tese (Doutorado em Educação). UERJ, Rio de Janeiro.

Identificação docente nas políticas curriculares para formação de professores. 
Projeto de Pesquisa apresentado ao CNPq (disponível em www.curriculo-uerj.pro. br), 2014b.

CUNHA, Érika Virgílio Rodrigues da. Cultura, contexto e a impossibilidade de uma unidade essencial para o currículo. Currículo sem Fronteiras, v. 15, n.3, p. 575-587, set./ dez. 2015.

CUNHA, Kátia Silva; DA Silva, Janini de Paula. Sobre base e bases curriculares, nacionais, comuns: de que currículo estamos falando? Revista e-Curriculum, São Paulo, v. 14, n. 4, p. 1236- 1257, out./ dez. 2016.

DERRIDA, Jacques. Gramatologia. São Paulo: Perspectiva, 2011.

FREITAS, Luiz Carlos de. BNCC: sob nova direção. Disponível em: https:// avaliacaoeducacional.com/2016/05/31/bncc-sob-nova-direcao/.Acesso em 24 de setembro de 2016.

GIACAGLIA, Mirta. Política e subjetividade no pensamento de Ernesto Laclau. In: RODRIGUES, Léo Peixoto; MENDONÇA, Daniel de. Ernesto Laclau e Niklas Luhmann: pós-fundacionismo, abordagem sistêmica e as organizações sociais. Porto Alegre: EDIPUCRS, 2006, p. 100- 114.

LACLAU, Ernesto. Razão Populista. Trad. Carlos Eugênio Marcondes de Moura. São Paulo: Três Estrelas, 2013.

LACLAU, Ernesto; MOUFFE, Chantal. Hegemonia e Estratégia Socialista. São Paulo: Intermeios; Brasília: CNPq, 2015.

LOPES, Alice Casimiro. Por um currículo sem fundamentos. Linhas Críticas (UnB), Brasília, v. 21, p. 445- 466, 2015.

LOPES, Alice Casimiro; MACEDO, Elizabeth. Teorias de currículo. São Paulo: Cortez, 2011.

MACEDO, Elizabeth. Por uma política da diferença. Cadernos de pesquisa, São Paulo, v. 36, n. 128, p. 327-356, maio / ago. 2006 a.

. Currículo como espaço-tempo de fronteira cultural. Revista Brasileira de Educação, Campinas, v.11, n. 32, p. 285- 372, maio/ ago. 2006b.

. Como a diferença passa do centro às margens nos currículos: o exemplo dos PCN. Educ. Soc., Campinas, vol. 30, n. 106, p. 87-109, jan./abr. 2009.

. Base Nacional Curricular Comum: novas formas de sociabilidade produzindo sentidos para educação. Revista E-Curriculum, São Paulo, v.2, n.3, p.1530-1555, out./dez., 2014. 
- Base Nacional Comum para currículos: direitos de aprendizagem e desenvolvimento para quem? Educ. Soc., Campinas, v. 36, n. 133, p. 891-908, out.-dez. 2015.

MAINARDES, Jefferson. A abordagem do ciclo de políticas: uma contribuição para análise de políticas educacionais. Ed. Soc., Campinas, v. 27, n. 94, p. 47-69, jan./ abr. 2006.

MARCHELLI, Paulo Sérgio. Da LDB 4.024/ 61 ao debate contemporâneo sobre as bases curriculares nacionais. Revista E-Curriculum, São Paulo, v.2, n.3, p.14801511, out./dez., 2014.

MENDONÇA, Daniel de; RODRIGUES, Léo Peixoto (orgs.). Pós-Estruturalismo e Teoria do Discurso: em torno de Ernesto Laclau. Porto Alegre: EDIPUCRS, 2008, p. 25-34.

MILLER, Janet. Teorização do currículo como antídoto contra/ na cultura da testagem. Revista E-Curriculum, São Paulo, v.2, n.3, p.2043-2063, out./dez., 2014.

OLIVEIRA, de Ana.; LOPES, Alice Casimiro. A abordagem do ciclo de políticas: uma leitura pela teoria do discurso. Cadernos de Educação, Pelotas, v. 38, p. 19-41, jan./ abr. 2011.

PARAÍSO, Marlucy Alves. A ciranda do currículo como gênero, poder e resistência. Currículo sem Fronteiras, v. 16, n. 3, p. 388- 415, set./ dez., 2016.

PEREIRA, Fábio de Barros.; OLIVEIRA, Inês Barbosa. de. Ponderações ao currículo mínimo da rede estadual do Rio de Janeiro: uma contribuição ao debate em torno da base comum nacional. Revista E-Curriculum, São Paulo, v.2, n.3, p.1669-1692, out./dez., 2014.

PEREIRA, Talita Vidal; COSTA, Hugo Heleno Camilo; CUNHA, Érika Virgílio da. Uma base à Base: quando o currículo precisa ser tudo. Revista Educação Pública, Cuiabá, v. 24, n. 56, p. 455-469, maio/ ago. 2015.

RIBEIRO, William de Goes. Remobilizando a pesquisa com o pós-estruturalismo: quando a diferença faz toda a diferença. Currículo sem Fronteiras, v. 16, n. 3, p. 542- 548, set./ dez., 2016.

SUSSEKIND, Maria Luiza. As (im) possibilidades de uma base comum nacional. Revista E-Curriculum, São Paulo, v.2, n.3, p.1512-1529, out./dez., 2014. 
Recebido em fevereiro de 2016

Aprovado em junho de 2017

William de Goes Ribeiro é bolsista PDJ com apoio do CNPa, doutor em educação pelo PPGE - UFRJ e participa do grupo de pesquisa Currículo, Subjetividade e Diferença (Proped- Uerj), coordenado por Elizabeth Macedo. Professor Adjunto da Universidade Federal Fluminense (UFF) onde é integrante do Grupo de Pesquisas Curriculares (GPeC) do Instituto de Educação de Angra dos Reis (IEAR), coordenado por Clarissa Craveiro.

E-mail: wgribeiro@id.uff.br.

Clarissa Bastos Craveiro é bolsista PDJ com apoio do CNPq, doutora pelo PropedUerj e participa do grupo de pesquisa Políticas de Currículo e cultura (Proped-Uerj), coordenado por Alice Casimiro Lopes. Professora adjunta da Universidade Federal Fluminense (UFF) onde coordena o projeto Identificação docente nas políticas curriculares para formação de professores. E-mail: clarissacraveiro@id.uff.br 